\title{
A caricatura entre o palco da vida e o teatro em cena
}

\author{
Maria Helena Serôdio
}

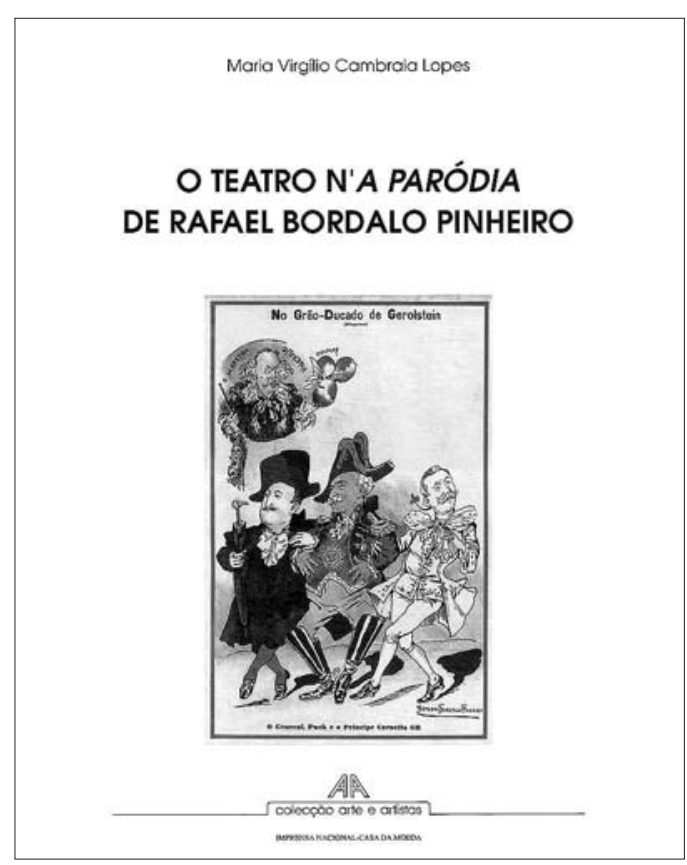

Foi um encontro feliz: no ano em que se celebrava o $1 .{ }^{\circ}$ centenário da morte de Rafael Bordalo Pinheiro, registouse uma convergência institucional entre a Imprensa Nacional - Casa da Moeda e o Centro de Estudos de Teatro (da Universidade de Lisboa) através de um protocolo, no âmbito do qual surgiu a publicação 0 teatro n'A Paródia de Rafael Bordalo Pinheiro, de Maria Virgílio Cambraia Lopes, que é uma versão revista da sua dissertação de mestrado em Estudos de Teatro, apresentada e defendida em 2003 (e que Luiz Francisco Rebello arguiu de forma atenta e brilhante).

Esta convergência institucional não opera, todavia, de forma avulsa ou inesperada. Há todo um historial de cuidada atenção ao teatro por parte da editora (fruto indesmentivel do empenho do Dr. Braz Teixeira, seu Director), e há, por parte do Centro, um trabalho continuado na preparação, fixação, e edição critica de textos de teatro, entre outros trabalhos de investigação que por lá se vão fazendo. Uma afloração visivel da compatibilidade de esforços foi a edição de Gil Vicente em 5 volumes em 2002 - As obras de Gil Vicente - com direcção científica de José Camões, a que, de resto, se seguiu, em 2003, a publicação em dois volumes das actas do Congresso Internacional Gil Vicente 500 anos depois, promovido pelo Centro de Estudos de Teatro na Faculdade de Letras de Lisboa.

\author{
Maria Virgílio Cambraia Lopes, $O$ teatro \\ n' A paródia de Rafael Bordalo Pinheiro, \\ Lisboa, Imprensa Nacional - Casa da Moeda, \\ 2005, $330 \mathrm{pp}$.
}

Estão, portanto, as duas instituições em excelente companhia, e a caminhada promete ser de incentivo mútuo.

0 livro de Maria Virgílio Cambraia Lopes constitui uma perspectivação interessante e original sobre a relação do periódico A paródia - que se publicou entre 1900 e 1907 - com o teatro em Portugal nas vertentes várias em que essa articulação é possivel de referir: quer no modo como o teatro "se intromete na [sua] estrutura" (p. 15), quer no modo como a publicação via a actividade teatral na sua figuração plural. Nesse sentido identificam-se, neste periódico, os artistas, dramaturgos, críticos e demais intervenientes na cena teatral de então, mas também os espectáculos, as salas de teatro, e as muitas convenções que organizavam o tecido cultural e artístico da altura.

0 estudo trata, portanto, de inventariar procedimentos de "interferência" produtiva: quer localizando nas caricaturas de Bordalo (e seus colaboradores) - e nos textos que as acompanham - uma forma de documentar, de forma imaginativa e crítica, a realidade artística desse tempo, quer analisando a contaminação de processos que torna a matéria iconográfica do periódico um modo de encenação do real (e esse na sua mais larga e momentosa ocorrência política).

E uma das primeiras impressões que nos deixa este livro de Maria Virgílio é a "importação" diligente dessas articulações. Com efeito, ele é em si um precioso auxiliar documental (facultando-nos índices de peças e espectáculos citados, bem como a lista dos profissionais ligados ao teatro que são nomeados no periódico), mas é também uma visão cúmplice do olhar d'A paródia. E é nesse sentido que aferimos os curtos resumos que acompanham os títulos de cada um dos cinco capítulos do livro', ou o carácter sucinto de cada subalínea, ou o indisfarçável gosto com que cita, parafraseia e comenta algumas declarações, legendas ou ilustrações do periódico.

Esse esforço e essa atenção são prelúdio elucidativo de um magnífico conjunto de 79 ilustrações que o volume inclui entre as páginas 209 e 285 e que a qualidade do papel couché aqui usado vem realçar ainda mais.

Por tudo isto se dirá que, sendo embora um trabalho realizado no contexto académico (com as exigências de rigor documental e ensaístico que isso implica), o livro se posiciona também na relação com o objecto que estuda
1 - Rafael Bordalo

Pinheiro; II - A paródia; III - 0 teatro e a estrutura interna d' A paródia; IV 0 olhar d'A paródia; V Da teatralidade do olhar d' A paródia. 
como parceiro de um olhar lúdico, certeiro na mirada, aforístico na expressão.

Parte, é certo, e como não podia deixar de ser, de bibliografia existente que tem estudado a obra de Bordalo - com destaque natural e justo para a ensaística de José Augusto França -, e passa em revista - ainda que breve - o envolvimento do caricaturista com o teatro: a sua estreia fugaz no teatro amador, as ilustrações várias de publicações de teatro, os figurinos que desenha, as decorações que propõe para salas de teatro, as transferências entre títulos de trabalhos seus e espectáculos levados à cena em Lisboa e, enfim, o "regime" de convivência boémia e divertida que Bordalo foi mantendo com os fazedores de teatro.

0 trabalho a que procede Maria Virgílio estuda o perfil da publicação, caracteriza o seu posicionamento político (que embora plural, ou plurivocal, não deixa de ser satírico), refere a sua episódica confrontação com a censura (em 1902, decorrente de uma caricatura do rei D. Carlos feita por Manuel Gustavo), enumera as suas rubricas fixas, e assinala os ecos do teatro na estrutura da revista: nos títulos, nos figurinos, nos anúncios, nos artigos de opinião, e mesmo na dramaturgia própria que a revista desenvolve. Mas este estudo localiza também o progressivo afastamento do topos do teatro após a morte de Bordalo em 1905, e isso tanto como matéria de que se fala(va), como de procedimento editorial que toma(va) de empréstimo processos especificos da actividade teatral.

$\mathrm{Na}$ atenção que o periódico dedica aos teatros é particularmente curiosa a análise do discurso crítico que dá testemunho de eleger critérios bem diferentes consoante escrevesse sobre uma actriz ou um actor: no $1 .{ }^{\circ}$ caso o critério é a beleza (visivel nas formas), no $2 .^{\circ}$ é a arte "viril" de esmagar ou subjugar a plateia.

Interessante é também a caracterização que faz da criação dramática, dando conta do incontornável e persistente gosto pelo dramalhão a ocupar muitas das salas de teatro em Lisboa. Exemplo disso era em 1900 a programação prevista para o Teatro do Príncipe Real, manifestamente insistente na desgraça infantil: Duas órfãs, O enjeitado, Infância desvalida, A creche, Sanatório para crianças escrafulosas.

Mas se este tardo-romantismo teimava em ocupar monocordicamente o gosto dominante - para desespero de quem achava que o teatro deveria alegrar a vida e que já bastava de receitas antigas - a verdade é que o assomo do simbolismo à Maeterlinck surgia aos colaboradores d' A paródia como pura "demência, delírio, incoerência, disparate, desconchavo", "sem pés nem cabeça" (p. 81).

De mais enfermidades estava, porém, o teatro cheio, como a voga - provinciana - das muitas traduções (enfim, o enraizado deslumbramento pelo estrangeiro) e que ainda por cima eram de má qualidade. $\mathrm{E}$ isto a ponto de contagiarem também os críticos, como aquele que referiu - presume-se que com seriedade e circunspecção -, a propósito de uma récita no D. Maria, como sendo o Frei Luis de Sousa "um chefe d' obra" (cit. pp. 68 e 112).

Outros achaques acometiam ainda a vida teatral entre nós por esse tempo: as precárias condições das casas de espectáculo, a deficiente preparação dos artistas, a fraca ilustração do público, a impreparação e conivência de alguns críticos, a inaceitável interferência dos censores, o peso dos impostos que recaíam sobre as empresas de teatro, a ingerência nas artes por parte do governo, entre mais algumas maleitas que iam sendo denunciadas no periódico em análise.

Mas para além desta veia satírica na visão do teatro que então se praticava, uma outra perspectiva crítica ocupou as páginas d'A paródia: a de olhar o palco da história a partir da gramática do teatro.

Assim se transferia o nome de personagens de dramas célebres para as figuras de políticos (com intencionais conotações), ou títulos de obras e vocabulário específico do teatro para acontecimentos da vida política. Mas assim também se confundia Parlamento e casa de espectáculos, ou se criavam enquadramentos de palco (com bambolinas, panos de boca ou figurinos e adereços vários) para a caricatura de estadistas em acção.

A identificação destes procedimentos leva Maria Virgílio a levantar a questão - pertinente mas não fácil de provar - de "saber em que medida A paródia, servindose da crítica humorística (através da caricatura, mas também do dito, da anedota ...), terá contribuído para a difusão de um imaginário colectivo que se revê na representação da vida política e social como um vasto teatro" (p. 199).

É evidente que este é um topos que bem recordamos do verso shakespeariano "The world is a stage" (As You Like I, II, vii, $139 \mathrm{ss}$ ), que vingou no imaginário barroco, e que no seu sentido sociológico foi bem fixado há 50 anos por Erving Goffman (A apresentação do eu na vida de todos os dias, 1959), fazendo hoje parte do "arsenal" dos procedimentos da nossa imputada pós-modernidade. Mas esta equação surge aqui, neste estudo da Maria Virgílio, redimensionada numa outra articulação: entre o real, o teatro e a caricatura.

Por tudo o que aqui ficou dito, é justo concluir que o presente estudo faz d' A paródia uma análise cuidada e minuciosa, mas também cúmplice e festiva, dando assim testemunho da importância de Bordalo para conhecermos o teatro do seu tempo: tanto o que se viu em palco, como o que identificou na cena política. Sempre num vaivém inventivo, de pendor deliciosamente satírico, de quem no teatro vê a vida, e na vida o teatro. 